Research news and notes

\section{AMERICAN GEOLOGICAL INSTITUTE BIBLIOGRAPHIC DATA BANK}

In response to a request from the Acquisitions Librarian of the American Geological Institute, a complimentary copy of each issue of Bulletin of the Society will be sent to the American Geological Institute, so that its contents can be abstracted and indexed for magnetic tape storage in the A.G.I. bibliographic data bank of the earth sciences. The A.G.I. collection is the source of the Geological Society of America's Bibliography and Index of Geology, and a source of other mission oriented bibliographies. The data collection is translated to a machine readable format and distributed in tape form to libraries and institutions for the use of research scientists. Its contents are also available for retrospective search services and for selective dissemination of information.

The Editor replied to the letter from the A.G.I. advising that the Committee of the Society was pleased to arrange for dispatch of a complimentary copy of each issue of the Bulletin for the purpose requested. He also invited the A.G.I. Librarian to prepare a short note for publication in the Bulletin to explain the operation and breadth of coverage of the A.G.I. data bank, the categories of information specifically for or related to earthquakes, and the procedure a library or institute in New Zealand could follow to request supply of tapes in machine-readable format, where information is desired here in specific instances. The following reply has been received.

\author{
American Geological Institute \\ 2201 M Street N.W. \\ Washington D.C. 20037 \\ December 8, 1969.
}

"Your recent letter addressed to Mrs Senterfitt, has been called to my attention. The AGI data bank now contains about 57,000 bibliographic references covering the geological literature of 1967, 1968 and 1969. Beginning with $1970,40,000$ to 50,000 further references of the current literature will be input each year. Toward the end of 1970 or at the beginning of 1971, we hope to begin including on magnetic tape the bibliographic references of the significant geologic back literature to the beginning of the century or earlier. We estimate that half a million references in the latter category will be recaptured over a period of years. All of the material input to a tape will be stored together with indexes to a depth and specificity that will permit retrieval for research purposes.
The file will contain as complete a coverage of earthquake and seismologic references as we can obtain. We will be able to supply full sets of the tapes in machine readable format, or sub-sets pertaining to special disciplines, geographic areas or subject topics. The tapes will be offered for sale at a cost of $\$ 0.20 \mathrm{U} . \mathrm{S}$. for each bibliographic-entry contained.

We shall be very pleased to send you further descriptive information as it becomes available or to answer any further questions that occur to yourself or to the Society.

Sincerely,

Joel J. Lloyd

Director of Science Information. 